\title{
Intermediate Density Lipoprotein Cholesterol Measurement
}

National Cancer Institute

\section{Source}

National Cancer Institute. Intermediate Density Lipoprotein Cholestero/Measurement. NCI Thesaurus. Code C112325.

The determination of the amount of intermediate density lipoprotein present in a sample. 